FINANÇAS 


\title{
RELAÇÃO ENTRE CARACTERÍSTICAS DO CONSELHO DE ADMINISTRAÇÃO E MONITORAMENTO
}

\author{
RELATIONSHIP BETWEEN CHARACTERISTICS OF THE BOARD OF DIRECTORS \\ AND MONITORING
}

Keysa Manuela Cunha de Mascena

Universidade de São Paulo

Simone Ruchdi Barakat

Universidade de São Paulo

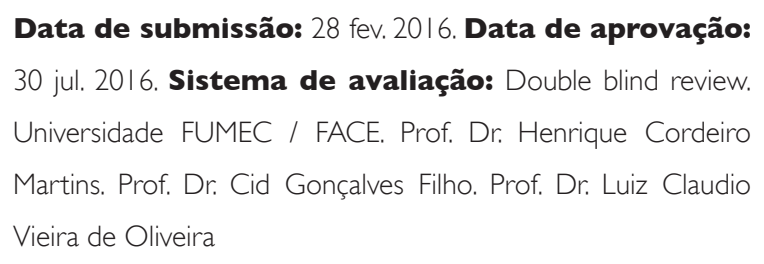

Adalberto Américo Fischmann

Universidade de São Paulo

RESUMO

O objetivo deste estudo foi analisar a relação entre características do conselho de administração (independência e dualidade do papel de CEO) e o monitoramento em empresas listadas na BM\&FBovespa. Como objetivo secundário, verificou-se se a concentração de propriedade modera as relações entre a independência do conselho e o monitoramento e entre a dualidade e o monitoramento. As hipóteses da pesquisa foram testadas em uma amostra de 287 empresas listadas. Os resultados permitiram a confirmação da hipótese de que existe uma relação negativa entre dualidade do papel do CEO e monitoramento. Verificou-se que $87,1 \%$ das empresas analisadas têm propriedade concentrada. Nesse contexto, surge outro tipo de conflito entre os interesses dos acionistas majoritários e os interesses dos acionistas minoritários. $\mathrm{Na}$ amostra estudada, verificou-se que, quanto maior a proporção de ações controladas pelo acionista majoritário, menor o monitoramento da gestão.

\section{PALAVRAS-CHAVE}

Governança Corporativa. Monitoramento. Conselho. Concentração de Propriedade. Dualidade CEO. 


\section{ABSTRACT}

The aim of this study was to analyze the relationship between board of directors' characteristics (independence and CEO duality) and the monitoring in companies listed on the BM\&FBovespa. The secondary objective was to analyze the ownership concentration as a moderator of the relationship between board independence and monitoring and between CEO duality and monitoring. The hypotheses of the study were tested in a sample of 287 listed companies. The findings support the hypothesis that there is a negative relationship between CEO duality and monitoring. It was found that $87.1 \%$ of the analyzed companies have concentrated ownership. In this context, another type of conflict arises, among the interests of majority shareholders and the interests of minority shareholders. In the sample, it was found that the higher the proportion of shares controlled by the majority shareholder smallest is the monitoring.

\section{KEYWORDS}

Corporate Governance. Monitoring. Board. Ownership Concentration. CEO Duality.

\section{INTRODUÇÃO}

Após a crise financeira no final dos anos 2000, diversas questões relacionadas à transparência nas atividades do mercado financeiro emergiram e revelaram algumas fraquezas na governança corporativa das empresas que atuam nesse mercado. Muitos críticos, baseados no argumento de que a governança corporativa pode falhar, principalmente devido ao conflito de agência, questionaram se a governança corporativa é realmente capaz de assegurar os interesses dos investidores (ARMSTRONG; SPELLMAN, 20I3).

Diante do desafio de supervisionar os agentes, os acionistas possuem algumas formas de mecanismos de governança para monitorar a gestão, como a supervisão direta pelos acionistas, controle do conselho de administração e auditoria externa (DESENDER et al., 20 l3).

Porém, esses mecanismos não são utilizados da mesma forma por todas as em- presas. Apesar de enfrentarem dilemas comuns, como conflito de agência e dificuldade de gestão dos diversos interesses dos stakeholders, as empresas possuem características muito diversas umas das outras, como setor de atuação, tamanho e cultura. Portanto, não é possível formular uma regra para monitoramento de gestão que seja eficaz para todas elas (CLARKE, 2004). Algumas práticas serão eficazes e relevantes apenas em determinadas combinações, levando a diferentes padrões de governança corporativa (AGUILERA et al., 2008).

Seguindo essa lógica, uma questão debatida na literatura é se a função de monitoramento do conselho de administração é igualmente importante para todas as empresas, independentemente de sua composição do conselho de administração e estrutura de propriedade (DESENDER et al., 2013). Ou seja, a eficácia dos mecanismos de governança corporativa para monitora- 
mento da gestão está relacionada com a composição do conselho de administração e estrutura de capital da empresa?

Estudos realizados com empresas norte-americanas e europeias sugerem que a independência do conselho de administração está associada a maiores gastos com auditoria externa, uma vez que diretores independentes desejam proteger sua reputação (KNECHEL; WILLEKENS, 2006; BOO; SHARMA, 2008). Além disso, esperase que, em empresas onde o mesmo indivíduo ocupa o papel de CEO e de presidente do conselho, haja menor nível de auditoria externa, uma vez que a auditoria externa é um instrumento para supervisionar os gestores e pode apontar ineficiências ou irregularidades no desempenho gerencial (O'SULLIVAN, 2000). Outro achado é que, em empresas com estrutura de propriedade dispersa, o conselho tem maior probabilidade de enfatizar seu papel de controle, pois existe uma maior dependência no conselho para esse papel, uma vez que o monitoramento feito diretamente pelos acionistas é inviabilizado pela dispersão.

Este estudo teve como objetivo analisar a relação entre características do conselho (independência e dualidade do papel de CEO, ou seja, quando as funções de CEO e de presidente do conselho são exercidas pelo mesmo indivíduo) e o monitoramento realizado por empresas listadas na BM\&FBovespa.

Como objetivo secundário, foi analisado se a concentração de propriedade mode$\mathrm{ra}$ as relações entre a independência do conselho e o monitoramento, e entre a dualidade e o monitoramento. $\mathrm{O}$ monitoramento é mensurado neste estudo pela remuneração paga aos auditores externos, conforme proposto pela pesquisa de Desender et al. (20I3).
A contribuição deste artigo está na análise das características de empresas listadas, em âmbito brasileiro, em relação ao monitoramento da gestão. Neste sentido, permite descrever características do conselho, concentração de propriedade e monitoramento. $A$ independência do conselho e ausência da dualidade do papel de CEO estão relacionadas às boas práticas de governança, importantes para empresas em mercados emergentes.

\section{REFERENCIAL TEÓRICO}

Um dos conceitos mais importantes para a discussão do tema é o de governança corporativa.

\section{Governança Corporativa}

De acordo com a Organization for Economic Cooperation and Development (OECD), governança corporativa é o sistema pelo qual as empresas são dirigidas e controladas. A estrutura da governança corporativa especifica a distribuição de direitos e responsabilidades entre os diferentes participantes na empresa, como os conselheiros, gestores, acionistas e outros stakeholders, e explicita as regras e procedimentos para tomada de decisões em assuntos corporativos. Ao fazer isso, também promove a estrutura pela qual os objetivos da empresa são determinados e os meios para atingir esses objetivos e monitorar 0 desempenho (CLARKE, 2004).

A governança corporativa também possui implicações mais abrangentes e é fundamental para o bem estar econômico e social, pois, além de promover incentivos e medidas de desempenho para empresa, promove a "prestação de contas" e transparência para garantir a distribuição justa da riqueza resultante. Para isso, os direto- 
res das empresas são cobrados a balancear os interesses, muitas vezes concorrentes, de vários grupos que participam da empresa (CLARKE, 2004). Outros stakeholders, tais como empregados, comunidades, fornecedores e clientes, também têm interesses na forma como a empresa é dirigida, e as preocupações dessas partes interessadas devem, de algum modo, ser internalizadas (TIROLE, 2006).

Porém, a visão dominante, em economia, é que governança corporativa se refere às maneiras com as quais os fornecedores de capital das empresas asseguram que terão um retorno de seus investimentos. Além disso, a governança corporativa, nessa visão, estaria preocupada com as formas pelas quais os gestores da empresa se comprometem a devolver os fundos para investidores externos e, assim, atrair mais financiamento (TIROLE, 2006).

De acordo com essa visão, os gestores podem agir de várias formas, em desacordo com os interesses dos acionistas: esforço insuficiente; investimentos extravagantes; estratégias de entrincheiramento; e negócios com benefícios próprios. Diversas formas de governança disfuncionais podem ser destacadas: falta de transparência; altos níveis de compensação; relação tênue entre compensação e desempenho; manipulação de contabilidade, entre outras (TIROLE, 2006).

As teorias econômicas possuem limitações como má interpretação do princípio central da governança corporativa e, ao mesmo tempo, da complexidade do fenômeno. Reduzir as relações econômicas a uma série de contratos não permite a compreensão das complexas relações existentes na empresa e da necessidade de adaptação a mercados em constante mudança (CLARKE, 2004).

\section{Separação entre Controle e Gestão}

Uma questão central em estudos de governança corporativa refere-se à sobrevivência das organizações em que os agentes que tomam as decisões importantes não sofrem os efeitos substanciais decorrentes dessas decisões. Nessas organizações, a decisão e a sujeição ao risco estão separadas, ou seja, suas estruturas de contratos separam o controle das decisões e a gestão das decisões (FAMA; JENSEN, I 983).

O relacionamento de agência é um contrato no qual uma ou mais pessoas (principal) engajam outra pessoa (agente) para desempenhar alguma tarefa em seu favor, envolvendo a delegação de autoridade para a tomada de decisão. $O$ problema de agência ocorre quando os gestores tomam decisões com 0 intuito de maximizar sua utilidade pessoal e não a riqueza dos acionistas. Os custos de agência são custos em que os acionistas incorrem para alinhar os interesses dos tomadores de decisão (gestores) aos seus e representam a soma dos: a) custos de criação e estruturação de contratos entre o principal e o agente; b) gastos de monitoramento das atividades dos gestores pelo principal; c) gastos promovidos pelo próprio agente, para mostrar, ao principal, que seus atos não lhe serão prejudiciais; d) perdas residuais, decorrentes da diminuição da riqueza do principal por divergências entre as decisões do agente e as decisões que iriam maximizar a riqueza do principal (JENSEN; MECKLING, I 976).

Uma alternativa, para a explicação da motivação dos gestores defendida pela Teoria da Agência, foi oferecida pela "stewardship theory”. Nessa teoria, o gestor não é visto como um oportunista, mas como um agente que deseja fazer um "bom trabalho" e ser um "bom administrador" dos bens da em- 
presa. Portanto, não haveria nenhum problema inerente de motivação dos gestores, mas a questão principal é como os gestores podem conseguir o bom desempenho das empresas. Essa teoria defende que as variações de desempenho resultam da situação estrutural em que o gestor se encontra, a qual pode facilitar ou não sua ação efetiva.A discussão seria se a estrutura da organização ajuda o gestor a formular e a implementar os planos de alto desempenho corporativo (DONALDSON; DAVIS, 199I).

Para testar a lógica da teoria da agência que afirma que os gestores não agem com o objetivo de maximizar a riqueza dos acionistas, a menos que uma estrutura de separação de papéis de decisão seja implementada, Donaldson e Davis (I99I) buscaram evidências empíricas e encontraram uma correlação entre as estruturas organizacionais que possuem dualidade do papel do gestor (CEO) e o retorno financeiro aos acionistas. Os autores reconhecem que são necessárias mais pesquisas para confirmar que a "stewardship theory" explicaria melhor a realidade que a teoria da agência. Porém, pode-se considerar que o estudo contribui para a reflexão sobre a tendência de analisar o papel do CEO e as recompensas apenas sob a ótica da teoria da agência.

\section{O papel do Conselho de Administração}

Em princípio, o conselho de administração monitora a gestão em nome dos acionistas. Destina-se a definir ou, mais frequentemente, a aprovar as principais decisões de negócios e a estratégia corporativa, como: alienação de ativos, investimentos ou aquisições e ofertas públicas feitas pelos adquirentes. É também responsável pela compen- sação dos executivos, supervisão da gestão de riscos, e auditorias.Além disso, pode oferecer conselhos e conexões para a gestão. Para realizar essas tarefas, conselhos funcionam cada vez mais por meio de comissões, como as comissões de compensação, nomeação e de auditoria. Os conselhos têm sido tradicionalmente descritos como ineficazes e controlados pela gestão, em vez de controlar.Assim, recentemente, têm surgido muitos pedidos por conselhos mais responsáveis (TIROLE, 2006).

A literatura de governança corporativa considera a eficiência do conselho de administração como sua habilidade em desempenhar funções para garantir a prosperidade da empresa, agregar valor à organização, direcionar a empresa para seus objetivos ou favorecer o desempenho corporativo para atender os interesses dos acionistas e outros stakeholders. As funções do conseIho são direção (orientação estratégica da empresa) e controle (monitoramento da gestão para garantir que os objetivos estratégicos sejam alcançados), por meio de contrat a ção, compensação e substituição de CEO e diretores, aprovação de grandes iniciat i vas propostas pela administração, elaboração de relatórios aos acionistas, e asseguramento do cumprimento da lei. $A$ contribuição do conselho envolve qualidades e comportamentos dos membros para o bom desempenho de suas funções de direção e de controle (PETROVIC, 2008).

Porém, é importante ressaltar que o controle pelo conselho é muito mais amplo do que o monitoramento da gestão. Primeiro, ele deve abranger o monitoramento de todos os acionistas de referência, pois esses ta mbém podem buscar benefícios privados. Em segundo lugar, deve abranger o monitoramento de toda a organização, o 
que significa que o conselho deve assegurar a existência de um sistema eficaz de controle interno e gestão de risco. Finalmente, também deve abranger uma avaliação regular do próprio conselho e seus membros, como uma forma de melhorar sua eficácia (VAN DEN BERGHE; BAELDEN, 2005).

As reclamações típicas relacionadas ao comportamento do conselho de administração referem-se à falta de independência, atenção insuficiente e tendência de fuga do conflito. Tendo em vista essas considerações, pode parecer que os conselhos não têm qualquer eficácia. Porém, eles interferem em algumas decisões, como afastar gerentes com baixo desempenho, por exemplo. É importante ressaltar, assim, que a relação entre diretores e gestão pode ser rompida, principalmente durante crises (TIROLE, 2006).

É importante ressaltar que os gestores recomendam indivíduos, para o conselho de administração, que não tenham conflitos de interesse e que não estejam comprometidos demais, ao ponto de serem obrigados a aceitar todas as propostas da gestão nas reuniões do conselho. Outro aspecto é o escopo dos códigos. Os códigos não são apenas feitos para os conselhos de administração. Eles também incluem, por exemplo, recomendações sobre relatórios (governança auditoria, relatórios financeiros), compensação de executivos, acionistas com direito a voto, etc. Em 2004, cinquenta países já tinham seu próprio código de governança. Esses códigos costumam emanar dos órgãos reguladores, associações de investidores, a própria indústria e organizações supranacionais (TIROLE, 2006).

Com relação ao ativismo dos investidores, o monitoramento ativo requer controle. O monitoramento por si só não altera a política corporativa. Para implementar novas ideias ou para se opor a políticas ruins dos gestores, o monitor ativo deve ter o controle, que pode vir em duas formas: formal e real. O controle formal é exercido pela família proprietária da maioria das ações com direito a voto, pela matriz de um conglomerado, ou por um capitalista com direitos de controle explícito sobre uma empresa startup. $O$ controle formal permite, assim, a um grande proprietário, implementar diretamente mudanças que considera necessárias. Por outro lado, o controle real é exercido por um proprietário minoritário, que convence outros proprietários, ou pelo menos uma fração deles, para que seja suficiente para criar uma maioria dissidente, de que há uma necessidade de intervenção. $A$ força com que um proprietário minoritário é capaz de convencer outros proprietários a se moverem contra a gestão depende de dois fatores: facilidade de comunicação e de construção de coalizões com outros investidores, e congruência de interesses entre os proprietários (TIROLE, 2006).

\section{Monitoramento, Conselho e Estrutura de Propriedade}

Desender et al. (20I3) defendem que a eficácia dos mecanismos de governança corporativa deve ser considerada em relação à estrutura de propriedade da empresa. Dentre os mecanismos, os autores focam a função de monitoramento do conselho de administração, medido como a remuneração à auditoria externa contratada pelo conselho. Os autores destacam que, embora as pesquisas se concentrem mais na relação entre estrutura de propriedade e composição do conselho com o desempenho da empresa, é interessante analisar a 
relação com aspectos do comportamento do conselho, como a decisão sobre contratar auditoria externa, relacionada a seu papel de monitoramento e controle.

O modelo conceitual, proposto por Desender et al. (20I3), será considerado nesta pesquisa, adaptando-se a variável moderadora, conforme apresentado na Figura I.

No modelo representado na Figura I, Desender et al. (20I3) defendem que a remuneração dos serviços de auditoria externa, proxy da decisão do conselho em aumentar o monitoramento da gestão, é influenciada por características do conseIho, como independência e dualidade CEO. A concentração de propriedade é moderadora da relação entre características do conselho.As relações propostas na Figura I serão desenvolvidas teoricamente nas subseções seguintes.

\section{Independência do conselho de administração}

Estudos realizados mostraram que a independência do conselho de administração está associada a maiores remunerações de auditoria externa. Esses estudos sugerem que conselheiros independentes demandam uma garantia adicional de um auditor externo para protegerem seu capital reputacional (BOO; SHARMA, 2008). Carcello et al. (2002) mostraram que conselhos tendem a conferir maior apoio à auditoria externa quando os diretores estão mais preocupados em exercer seu papel de monitoramento. Portanto, a independência do conselho estaria associada a maiores taxas de auditoria, uma vez que esses conselheiros possuem o desejo de proteger sua reputação.

Knechel e Willekens (2006) argumentam que isso ocorre porque a auditoria externa é maior em situações em que há envolvimento de stakeholders com perfis de risco diversos e que podem transferir parte do custo de monitoramento para outros stakeholders, ou seja, os conselheiros independentes exigirão garantia adicional para proteger a sua reputação, especialmente quando o custo é suportado pelos acionistas, e não pelos próprios conselheiros.

Carcello et al. (2002) defendem que um conselho mais independente, diligente $e$ profissional demanda uma maior qualidade de auditoria para proteger seu capital reputacional, evitar ações de responsabilidade legal e promover os interesses dos acionistas. Para esses autores, a taxa de

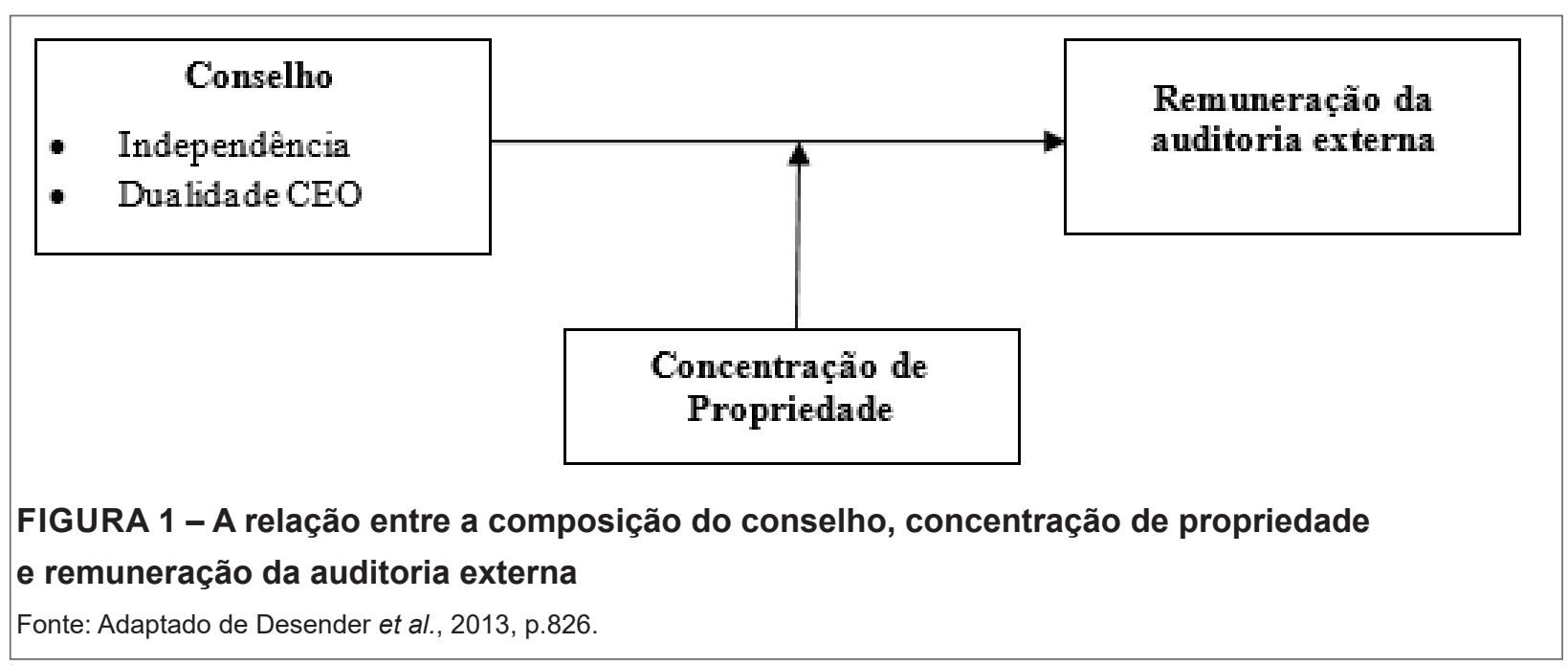


auditoria aumenta conforme os custos de auditoria adicional são repassados para os clientes.

Abbott et al. (2003), em seu estudo empírico, encontraram que a independência e a expertise em finanças dos conselhos estão significativamente e positivamente associadas com taxas de auditória. Além disso, Cohen et al. (2002) sugerem que os comitês de auditoria precisam do apoio do conselho para desempenhar as suas funções de forma eficaz.

Dessa forma, conforme proposto por Desender et al. (2013), sugere-se que, no contexto brasileiro, também ocorre a hipótese:

Hipótese I: Existe uma relação positiva entre independência do conselho de administração e remuneração da auditoria externa.

\section{Dualidade do papel do CEO}

Uma vez que a auditoria externa é um instrumento para supervisionar os gestores, os CEOs podem ter um forte incentivo para limitar a supervisão externa. Principalmente se as conclusões dos auditores puderem apontar ineficiências ou irregularidades no desempenho gerencial. Portanto, espera-se que a presença de um CEO dominante esteja negativamente associada com o nível de auditoria externa (O’SULLIVAN, 2000).

Seguindo essa lógica, Desender et al. (20l3) argumentam que, em situações em que a mesma pessoa ocupa o cargo de CEO e de presidente do conselho de administração, o nível de auditoria externa será menor, uma vez que essa pessoa tem maiores incentivos para evitar essa supervisão externa.A partir disso, sugere-se que, no contexto brasileiro, também ocorre a hipótese de Desender et al. (2013):
Hipótese 2: Existe uma relação negativa entre dualidade do papel do CEO e remuneração da auditoria externa.

\section{Concentração de Propriedade}

Em empresas com propriedade dispersa, o conselho tem maior probabilidade de enfatizar seu papel de controle, pois existe uma maior dependência no conselho para esse papel, uma vez que o monitoramento, feito diretamente pelos acionistas, é inviável (AGUILERA, 2005). Portanto, quando a expectativa de monitoramento pelo conselho é alta, os membros independentes do conselho são mais propensos a dedicar mais esforço nesse papel e a aumentar o escopo da auditoria. Em estruturas de propriedade mais concentradas, grandes investidores têm maiores possibilidades de coletar informação e monitorar a gestão diretamente, e, consequentemente, dependem menos do conselho para esse papel (DESENDER et al., 20 I3).

Além disso, a assimetria de informações entre gestores e diretores independentes, provavelmente, é maior em empresas com propriedade dispersa, incentivando os conselheiros independentes a exercer seu papel de monitoramento com maior fiscalização (ADAMS et al., 2010). A partir dessa lógica, as seguintes hipóteses, levantadas por Desender et al. (20l3), também podem ocorrer no contexto brasileiro:

Hipótese 3a: A relação positiva entre independência do conselho e remuneração da auditoria externa é fortalecida em empresas com estrutura de capital dispersa.

Hipótese $3 b$ : A relação negativa entre $a$ dualidade do papel do CEO e remuneração da auditoria externa é fortalecida em empresas com estrutura de capital dispersa. 


\section{MÉTODO DE PESQUISA}

Para testar empiricamente as hipóteses desta pesquisa, empreendeu-se uma pesquisa descritiva, com o uso de dados secundários. Uma vez que o objetivo da pesquisa é verificar se existe uma associação entre composição do conselho e estrutura de propriedade com remuneração da auditoria externa, foi utilizado o método de pesquisa hipotético-dedutivo. Nesse método, busca-se deduzir algo a partir da formulação de uma ou mais hipóteses que serão testadas, buscando regularidades e relacionamentos entre elementos (VERGARA, 20I I).

\section{Seleção da amostra}

A amostra selecionada para esta pesquisa é não probabilística, definida em função da disponibilidade de dados sobre pagamentos para empresas de auditoria e sobre estrutura de propriedade.As empresas analisadas foram selecionadas a partir do conjunto de empresas de capital aberto listadas na BM\&FBovespa. A amostra final desta pesquisa é composta por 287 empresas listadas na BM\&FBovespa.

\section{Modelo da pesquisa}

Foram testados dois modelos de regressão MQO (Mínimos Quadrados Ordinários) conforme proposto por parte do estudo de Desender et al. (2013), realizado em empresas listadas na França e na Espanha. Os dois modelos que serão replicados nesta pesquisa no contexto brasileiro são:

\section{Modelo I}

Remuneração auditoria $=f$ (Independência do conselho, Dualidade CEO, Concentração de propriedade, Controles)

\section{Modelo II}

Remuneração auditoria $=f$ (Independência do conselho, Dualidade CEO, Concentração de propriedade, Independência do conselho $\times$ Concentração de propriedade, Dualidade CEO $\times$ Concentração de propriedade, Controles)

\section{Coleta de dados}

A coleta de dados sobre pagamentos à auditoria externa foi realizada utilizando as informações disponíveis nos formulários de referência publicados pelas empresas no site da BM\&FBovespa. A coleta de dados sobre a estrutura de propriedade e composição do conselho foi realizada a partir da base de dados Econoinfo, que divulga informações sobre a estrutura de governança corporativa das empresas listadas. As informações financeiras foram coletadas na base Economatica, referentes ao ano de 2013.

O Quadro I apresenta as variáveis da pesquisa e a fonte dos dados.

\section{Variáveis da pesquisa}

Remuneração dos auditores externos: A variável dependente foi obtida consultando-se o formulário de referência de cada uma das empresas listadas no site da BM\&FBovespa. Na seção auditores independentes, do formulário de referência, é divulgada informação sobre o nome da auditoria contratada e a remuneração anual. A remuneração foi obtida na moeda Real, referente ao ano de 2013. Nos testes de hipóteses, utilizou-se o logaritmo natural dos valores em reais extraídos do formulário de referência.

Independência do conselho: Verificou-se a composição do conselho de cada uma das empresas listadas. $\mathrm{Na}$ base Econoinfo, obteve-se nome e perfil dos con- 
QUADRO 1 - Variáveis da pesquisa

\begin{tabular}{|c|l|l|}
\hline \multicolumn{1}{|c|}{ Tipo } & \multicolumn{1}{|c|}{ Nome da variável } & \multicolumn{1}{|c|}{ Fonte dos dados } \\
\hline Dependente & Remuneração dos auditores externos & Formulário de Referência \\
\hline Independente & Independência do conselho & Econoinfo \\
\hline Independente & Dualidade CEO & Econoinfo \\
\hline Independente & Concentração de propriedade & Econoinfo \\
\hline Controle & Tamanho (InAtivo) & Economatica \\
\hline Controle & Retorno do ativo (ROA) & Economática \\
\hline Controle & Big 4 & Formulário de referência \\
\hline Controle & Setor & BM\&Fbovespa \\
\hline
\end{tabular}

Fonte: Elaborado pelos autores.

selheiros de administração para cada uma das empresas da amostra. A partir das informações, somou-se o número de conseIheiros independentes e o número total de conselheiros. A variável independência do conselho foi definida como a razão entre o número de conselheiros independentes e o número total de conselheiros.

Dualidade CEO: $\mathrm{Na}$ base de dados Econoinfo, verificou-se o nome e perfil do presidente do conselho e do CEO da companhia. A variável dualidade é binária, assumindo o valor I se os cargos de presidente do conselho e CEO fossem ocupados pela mesma pessoa, e valor 0 , caso fossem ocupados por pessoas diferentes.

Concentração de propriedade: A variável foi obtida na base Econoinfo, que descreve quais os acionistas de cada uma das empresas e o percentual de suas ações com direito a voto. Duas variáveis foram definidas para concentração de propriedade. A primeira variável foi definida como o valor percentual de ações com direito a voto do acionista que detém o maior número de ações (variável métrica). A segunda variável foi definida como binária, assumindo valor I caso a companhia apresentasse acionista majoritário concentrando $20 \%$ das ações ou mais, e, valor 0 , caso não houvesse acionista com concentração de pelo menos $20 \%$ das ações.

Big 4: O nome da empresa que prestou serviços de auditoria foi obtido consultando-se a seção auditores independentes do formulário de referência de cada uma das empresas listadas no site da BM\&FBovespa. A variável Big4 é binária, assumindo o valor I caso fosse verificada uma das quatro grandes empresas de auditoria: KPMG, Ernst \& Young, PricewaterhouseCoopers e Deloitte. Para empresas diferentes dessas quatro, a variável assume o valor 0 . A variável Big4 é comumente usada em estudos sobre auditoria e empregada por Desender et al. (20/3).

Tamanho: A proxy para a variável de controle tamanho da empresa foi definida como o logaritmo natural do ativo total no exercício de 2013.

Setor: A classificação setorial definida pela BM\&FBovespa foi utilizada como variável de controle.

Retorno do ativo (ROA): obtida na base de dados Economatica, referente ao ano de 20I3. É uma variável de controle utilizada por Desender et al. (20I3) por ser considerada uma medida de risco para o auditor. 


\section{RESULTADOS}

As hipóteses da pesquisa foram testadas na amostra de 287 empresas listadas na BM\&FBovespa. As estatísticas descritivas dos dados coletados são apresentadas e, em seguida, os resultados alcançados são analisados.

\section{Descritivas}

As características da amostra para as principais variáveis da pesquisa (dependente, independentes e de controle), são apresentadas na Tabela I, em termos de média, desvio-padrão, mínimo e máximo das variáveis métricas.

Nas estatísticas descritivas apresentadas, pode-se destacar a variável concentração de propriedade - percentual (concP), com uma média de $57,5 \%$ e elevado desvio padrão. $O$ percentual revela a quantidade proporcional de ações do acionista majoritário.A média revela a alta concentração de propriedade das empresas da amostra, característica comum em empresas de capital aberto brasileiras. A Tabela 2 apresenta a frequência das variáveis binárias (dummy) utilizadas neste estudo.
Conforme observado na média de ações de propriedade do sócio majoritário, a variável dummy, que assume valor um se a empresa tem controlador com mais de $20 \%$ das ações, revela um número alto de empresas com propriedade concentrada. Quanto ao tipo de propriedade, o tipo com o maior número de empresas é a propriedade familiar, que corresponde a $40,8 \%$ do total da amostra.A Tabela 3 apresenta a correlação entre as variáveis dependentes e independentes.

$\mathrm{Na}$ Tabela 3, observa-se correlação estatisticamente significante em diversos pares de variáveis. A maior correlação encontrada é entre as variáveis de concentração de propriedade percentual e dummy $(0,624)$, que serão utilizadas separadamente nos modelos. No entanto, para fins de atendimento aos pressupostos da regressão múltipla, nos modelos testados foi calculada a estatística VIF, para verificar se há presença de multicolinearidade.A média VIF do Modelo I é I,39 e do Modelo II é 3,08, ambos inferiores a 5 , o que indica ausência de multicolinearidade.

Observa-se, na Tabela 3, que a variável dependente de remuneração da auditoria

TABELA 1 - Estatísticas descritivas das variáveis métricas

\begin{tabular}{l|c|c|c|c}
\hline Variável & Média & Desvio padrão & Min & Max \\
\hline Remuneração da auditoria (Inaudit) & 13,06752 & 1,574804 & 8,748 & 19,242 \\
\hline Independência do conselho (indep) & 0,191742 & 0,211491 & 0 & 1 \\
\hline Concentração de propriedade - percentual (concP) & 57,5126 & 27,65251 & 5,03 & 100 \\
\hline Tamanho (tam) & 14,5857 & 2,417808 & 2,3026 & 20,87 \\
\hline ROA & $-7,2298$ & 76,37542 & $-834,62$ & 80,34 \\
\hline
\end{tabular}

Fonte: Elaborado pelos autores.

TABELA 2 - Estatísticas descritivas das variáveis binárias

\begin{tabular}{l|c|c|c|c}
\hline Variável & Não (0) & Sim (1) & Sim \% & Total \\
\hline Dualidade CEO (dual) & 242 & 45 & $15,7 \%$ & 287 \\
\hline Concentração de propriedade - dummy (concD) & 37 & 250 & $87,1 \%$ & 287 \\
\hline big4 & 67 & 220 & $76,7 \%$ & 287 \\
\hline
\end{tabular}

Fonte: Elaborado pelos autores. 
TABELA 3 - Correlações

\begin{tabular}{c|c|c|c|c|c}
\hline & Inaudit & Indep & dual & concD & concP \\
\hline Inaudit & 1 & & & & \\
\hline indep & $0,304^{* * *}$ & 1 & & & \\
\hline dual & $-0,327^{* * *}$ & $-0,311^{* * *}$ & 1 & & \\
\hline concD & $-0,118^{* *}$ & $-0,326^{* * *}$ & $0,166^{* * *}$ & 1 & \\
\hline concP & $-0,273^{* * *}$ & $-0,441^{* * *}$ & $0,230^{* * *}$ & $0,624^{* * *}$ & 1 \\
\hline
\end{tabular}

${ }^{* *} \mathrm{p}<0.05^{* * *} \mathrm{p}<0.01$

Fonte: Elaborado pelos autores.

externa tem correlação negativa significante com dualidade e concentração de propriedade, e tem correlação positiva significante com independência do conselho.

\section{Resultados dos testes de hipóteses}

Os dois modelos, descritos na seção "Modelo da pesquisa", do método de pesquisa, foram empregados para testar as hipóteses da pesquisa.A Tabela 4 apresenta 0 resultado dos modelos.
Os resultados do Modelo I correspondem ao teste das hipóteses I e 2, enquanto os resultados do Modelo II correspondem ao teste das hipóteses $3 a$ e $3 b$. Esses resultados serão discutidos nas subseções a seguir.

\section{Relação entre independência do conselho e monitoramento}

Os resultados revelam que a primeira hipótese da pesquisa não é confirmada na amostra analisada no contexto brasileiro:

TABELA 4 - Resultado dos Modelos I e II

\begin{tabular}{|c|c|c|c|c|}
\hline \multirow{3}{*}{$\begin{array}{l}\text { VD } \\
\text { VI }\end{array}$} & \multicolumn{2}{|l|}{ Lnaudit } & & \\
\hline & \multicolumn{2}{|c|}{ Modelo I } & \multicolumn{2}{|c|}{ Modelo II } \\
\hline & Conc $>20 \%$ & Conc\% & Conc $>20 \%$ & Conc\% \\
\hline indep & 0,285391 & 0,089602 & 0,316474 & $-0,43043$ \\
\hline dual & $-0,35358^{* *}$ & $-0,31819^{* *}$ & $-0,35447^{* *}$ & $-0,49404$ \\
\hline conc & $-0,11428$ & $-0,00514^{* *}$ & $-0,10092$ & $-0,00775^{\star *}$ \\
\hline indep_conc & - & - & $-0,03864$ & 0,011689 \\
\hline dual_conc & - & - & 0 & 0,002983 \\
\hline tam & $0,512513^{* * *}$ & $0,506634^{* * *}$ & $0,512561^{* * *}$ & $0,501836^{* * *}$ \\
\hline roa & $-0,00384^{\star * *}$ & $-0,00378^{* * *}$ & $-0,00384^{* * *}$ & $-0,00379^{* * *}$ \\
\hline big4 & $0,5495^{* * *}$ & $0,561372^{* * *}$ & $0,550186^{* * *}$ & $0,563678^{* * *}$ \\
\hline set2 & $0,419841^{* *}$ & $0,387496^{\star *}$ & $0,420481^{* *}$ & $0,386453^{* *}$ \\
\hline set3 & 0,38305 & 0,338557 & 0,383805 & 0,327295 \\
\hline set4 & $0,362743^{* *}$ & $0,327796^{* *}$ & $0,363228^{* *}$ & $0,326013^{* *}$ \\
\hline set5 & $0,549675^{\star * *}$ & $0,481264^{* * *}$ & $0,550943^{* * *}$ & $0,458615^{\text {***}}$ \\
\hline set6 & 0,201188 & 0,194903 & 0,201522 & 0,196823 \\
\hline set7 & $0,447624^{*}$ & $0,455956^{*}$ & $0,44558^{*}$ & $0,451381^{*}$ \\
\hline set8 & 0,23885 & 0,217411 & 0,240339 & 0,210433 \\
\hline set9 & $-0,20689$ & $-0,24574$ & $-0,20746$ & $-0,23105$ \\
\hline set10 & $-0,56948^{\star \star \star}$ & $-0,56519^{* * *}$ & $-0,56988^{* * *}$ & $-0,55542^{\star * *}$ \\
\hline _cons & $5,085056^{* * *}$ & $5,412954^{\star * *}$ & $5,07161^{* * *}$ & $5,628007^{\star * *}$ \\
\hline
\end{tabular}

${ }^{*} p<0.10{ }^{* *} p<0.05 * * * p<0.01$

Fonte: Elaborado pelos autores. 
$(\mathrm{HI})$ Existe uma relação positiva entre independência do conselho de administração e remuneração com auditoria externa.

Verifica-se que a variável independência do conselho apresenta coeficiente sem significância estatística, ou seja, não se pode considerar com $95 \%$ de confiança que o coeficiente é diferente de zero. Esse resultado não confirma a hipótese de que quanto maior o percentual de conselheiros independentes, maior seria o volume das taxas pagas para a auditoria externa, visando a maior monitoramento da gestão.

O estudo realizado por Guerra, Fischmann e Koyama (20I4), uma survey com 122 executivos e conselheiros de 65 empresas listadas no Brasil, teve como resultado alcançado a constatação de que os conseIhos das empresas pesquisadas são compostos por uma maioria de conselheiros eleitos pelos sócios controladores e que há menos conselheiros independentes do que o recomendado. Observa-se que a independência do conselho e seus possíveis impactos permanece uma temática importante de investigação no contexto brasileiro.

$\mathrm{Na}$ amostra deste estudo, a proporção de conselheiros independentes, em média, é de 0,19 , com elevado desvio padrão $(0,21)$.A partir dessa característica, pode-se concordar com Guerra, Fischmann e Koyama (2014) quanto à baixa participação de conselheiros independentes nos conselhos de empresas listadas no Brasil. No entanto, a influência do nível de independência do conselho no monitoramento não pode ser encontrada nos testes empíricos realizados neste estudo, o que pode indicar que, embora existam poucos conselheiros independentes, o papel de monitoramento, considerado pela proxy de remuneração da auditoria externa, é exercido pelo conselho de administração.

\section{Relação entre dualidade do papel do CEO e monitoramento}

Os resultados revelam que a segunda hipótese da pesquisa é confirmada na amostra analisada: $(\mathrm{H} 2)$ Existe uma relação negativa entre dualidade do papel do CEO e remuneração com auditoria externa.

Verifica-se que a variável dualidade apresenta coeficiente negativo e significante nas regressões do Modelo I e em uma regressão do Modelo II. Esse resultado confirma a hipótese de que, nas companhias em que há dualidade do papel do CEO, o volume das taxas pagas para a auditoria externa é inferior ao das companhias em que não há dualidade, na amostra estudada.

Esse resultado corrobora a literatura, confirmando que, quando o CEO exerce o papel de presidente do conselho, pode haver um menor interesse por parte do gestor de que o conselho exerça um papel mais ativo no monitoramento da gestão, e esse monitoramento seria menor dada a influência que o gestor exerce no conselho, enquanto presidente. Esse comportamento refletiria um menor investimento em auditoria.

$\mathrm{Na}$ amostra deste estudo, há 45 casos de dualidade do papel de CEO (I5,7\%). No estudo de Guerra, Fischmann e Koyama (20I4), a dualidade é considerada como de baixa ocorrência, com sete (7) casos em 65 , ou seja, $10,7 \%$. Neste estudo, com uma amostra maior, registrou-se uma proporção maior de casos. Cabe ressaltar que, na pesquisa de Desender et al. (20/3), com 242 empresas listadas na França e Espanha, o percentual de empresas em que há dualidade é de $56 \%$, bastante superior ao registrado na amostra deste estudo (287 empresas listadas no Brasil). Portanto, dado que esta é uma das práticas não recomendadas de governança corporativa, ainda há um elevado 
número de ocorrência no Brasil, porém, se comparada a empresas em outros contextos, esta prática não é dominante.

Outro ponto a ser discutido, também levantado por Guerra, Fischmann e Koyama (20l4), é que, em alguns casos, pode haver estreitas relações entre o CEO e o chairman. Embora não sejam o mesmo indivíduo, podem ter relações familiares entre si, como entre pai e filho ou entre irmãos, ou ter relações com o sócio controlador. Esses tipos de caso podem influenciar o papel do conselho no monitoramento da gestão e podem constituir uma temática a ser analisada. $\mathrm{A}$ análise dessas relações pode ser incentivada pelos resultados obtidos neste estudo, de que há uma relação negativa entre dualidade e monitoramento na amostra pesquisada.

\section{Moderação da concentração de propriedade na relação entre a independência e dualidade do conselho e o monitoramento}

Os resultados revelam que a terceira hipótese da pesquisa, relacionada à independência do conselho, não é confirmada na amostra analisada: $(\mathrm{H} 3 \mathrm{a})$ A relação positiva entre independência do conselho e remuneração com auditoria externa é fortalecida em empresas com estrutura de capital dispersa.

Verifica-se que a interação entre a variável concentração de propriedade e independência do conselho apresenta coeficiente não significante nas duas regressões do Modelo II. Ou seja, não se pode considerar com $95 \%$ de confiança que o coeficiente é diferente de zero na amostra analisada. Este resultado não confirma a hipótese de que quanto maior o percentual de conseIheiros independentes em empresas de capital pulverizado, maior seria o volume das taxas pagas para a auditoria externa.
Os resultados também revelam que a terceira hipótese da pesquisa, relacionada à dualidade do papel do CEO, não é confirmada na amostra analisada: $(\mathrm{H} 3 \mathrm{~b}) \mathrm{A}$ relação negativa entre a dualidade do papel do CEO e remuneração com auditoria externa é fortalecida em empresas com estrutura de capital dispersa.

Verifica-se que a interação entre a variável concentração de propriedade e dualidade apresenta coeficiente não significante na segunda regressão do Modelo II. Ou seja, não se pode considerar com $95 \%$ de confiança que o coeficiente é diferente de zero na amostra analisada. Na primeira regressão do Modelo II, considerando-se a variável concentração de propriedade como variável binária (assumindo valor I para as companhias em que o principal acionista tem mais que $20 \%$ das ações), a variável de interação foi omitida. Isto ocorreu, pois, analisando-se a base de dados, verificou-se que todas as empresas com dualidade do papel do CEO também apresentavam propriedade concentrada.

Os resultados da moderação da variável concentração de propriedade não confirmam, na amostra pesquisada, que em empresas de capital disperso haveria maior volume de remuneração da auditoria externa, quanto maior o nível de independência do conselho, e haveria menor volume de remuneração da auditoria externa, quando houvesse dualidade do CEO. E, no último caso, reforça-se que, na amostra, as empresas de capital disperso não têm CEOs exercendo o papel de presidente do conselho, pois os casos de dualidade ocorreram apenas nas empresas de capital concentrado.

Analisando-se apenas a variável concentração de propriedade na segunda regressão do Modelo II, observa-se que o coe- 
ficiente é negativo e significante. Ou seja, quanto menor o percentual de ações do acionista principal, maior a remuneração da auditoria externa. Em outras palavras, esse resultado revela que, na amostra analisada, as empresas em que o acionista majoritário concentra um maior percentual de ações, há um menor nível de monitoramento da gestão, medido pelas taxas pagas à auditoria externa.

\section{CONCLUSÃO}

Economias em desenvolvimento, como - Brasil, estão recebendo uma proporção cada vez maior de investimento estrangeiro e de grandes grupos, como fundos de pensões, companhias de seguro e fundos de investimento. Para atender a padrões cada vez mais exigentes de governança corporativa, o monitoramento tem papel importante para minimizar riscos de fraude e perda de valor para os investidores.

Este estudo teve como objetivo analisar a relação entre independência do conselho e dualidade do papel de CEO e o monitoramento realizado por empresas listadas na BM\&FBovespa. Como objetivo secundário, foi analisado se a concentração de propriedade modera as relações entre a independência do conselho e o monitoramento e entre a dualidade e o monitoramento. $O$ monitoramento foi mensurado pela remuneração aos auditores externos, conforme proposto pela pesquisa de Desender et al. (20/3).

$\mathrm{Na}$ amostra analisada de 287 empresas listadas, os resultados permitiram a confirmação da hipótese de que existe uma re- lação negativa entre dualidade do papel do CEO e a remuneração da auditoria externa. As demais hipóteses da pesquisa não foram confirmadas na amostra analisada, em função de dados não significantes no modelo. No entanto, embora não confirmadas, podem fornecer evidências empíricas sobre o papel do conselho no monitoramento da gestão, no contexto brasileiro.

Uma alta concentração de propriedade é uma característica de empresas abertas em mercados emergentes (FAN; WONG, 2005). Verificou-se, na amostra, que $87,1 \%$ das empresas analisadas têm propriedade concentrada, ou seja, mais de $20 \%$ das ações são pertencentes ao acionista majoritário. Nesse contexto, outro tipo de conflito surge: entre os interesses dos acionistas majoritários e os interesses dos acionistas minoritários. $\mathrm{Na}$ amostra estudada, verificou-se que, quanto maior a proporção de ações controladas pelo acionista majoritário, menor a remuneração da auditoria externa, proxy do monitoramento da gestão.

Outra evidência é que a dualidade do papel do CEO tem influência negativa no nível de monitoramento. Esse achado indica que há oportunidades de pesquisas sobre como a dualidade influencia no papel do conselho e também sobre as possíveis influências quando há ausência de dualidade, mas há, porém, relações estreitas entre o CEO e o presidente do conselho, como relações familiares. Nesse sentido, futuros estudos podem aprofundar as análises e buscar ampliar a amostra para compreensão desse fenômeno, no contexto brasileiro. 
ABBOTT, L. J.; PARKER, S.; PETERS, G. F.; RAGHUNANDAN, K. The association between audit committee characteristics and audit fees. Auditing: A Journal of Practice \& Theory, [S. I.], v. 22, n. 2, p. 17-32, 2003.

ADAMS, R. B.; HERMALIN, B. E.; WEISBACH, M. S. The role of boards of directors in corporate governance: a conceptual framework and survey. Journal of Economic Literature, [S. I.], v. 48, n. I, p. 58-107, 2010.

AGUILERA, R. V. Corporate Governance and Director Accountability: An Institutional Comparative Perspective. British Journal of Management, [S. I.], v. 16, P. S39-S53, 2005.

AGUILERA, R. V.; FILATOTCHEV, I.; GOSPEL, H.; JACKSON, G. Contingencies, complementarities, and costs in corporate governance models. Organization Science, [S. I.], v. 19, n. 3, p. 475-492, 2008.

ARMSTRONG, P.; SPELLMAN, J. D. Thoughts on Corporate Governance and its Future. In: FONTES FILHO, J. R.; LEAL, R. P. C. (Org.). O Futuro da governança corporativa: desafios e novas fronteiras. São Paulo: IBGC, Ed. Saint Paul, 20 I3. v. I, p. 3 I-44.

BOO, E.; SHARMA, D. Effect of regulatory oversight on the association between internal governance characteristics and audit fees. Accounting \& Finance, [S. I.], v. 48, n. I, p. 5I-7I, 2008.

CARCELLO, J.V. et al. Board characteristics and audit fees. Contemporary Accounting Research,
[S. I.], v. 19, n. 3, p. 365-384, 2002. CLARKE, T. (Ed.). Theories of corporate governance: The philosophical foundations of corporate governance. Oxon: Routledge, 2004.

COHEN, J.; KRISHNAMOORTHY, G.; WRIGHT, A. M. Corporate Governance and the audit process. Contemporary Accounting Research, v. 19, p. 573-593, 2002.

DESENDER, K. A.; AGUILERA, R. V.; CRESPI, R.; GARCÍ-CESTONA, $M$.When does ownership matter? Board characteristics and behavior. Strategic Management Journal, [S. I.], v. 34, n. 7, p. 823842, 2013.

DONALDSON, L.; DAVIS, J. Stewardship Theory or Agency Theory: CEO Governance and Shareholder Returns. Australian Journal of Management, [S. I.], v. 16, n. I, June 199I.

FAMA, E. F.; JENSEN, M. C. Separation of Ownership and Control. Journal of Law and Economics, [S. I.], v. 26, 1983.

FAN, J. P. H.; WONG, T. J. Do external auditors perform a corporate governance role in emerging markets? Evidence from East Asia. Journal of Accounting Research, [S. I.], v. 43, n. I, p. 3572, 2005.

GUERRA, S.; FISCHMANN, A. A.; KOYAMA, S. M. The roles of the board of directors in listed companies in Brazil. Journal of Academy for Advancement of Business Research, [S. I.], v. 3, n. I, p.| I5-|30, 2014.
JENSEN, M. C; MECKELING, W. H. Theory of Firm: Managerial Behaviour, Agency Costs and Owner -ship Structure. Journal of Financial Economics, [S. I.], v. 3, n. 4, p. 305-360, 1976.

KNECHEL, W. R.; WILLEKENS, M. The role of risk management and governance in determining audit demand. Journal of Business Finance \& Accounting, [S. I.], v. 33, p. 1344-67, 2006.

O'SULLIVAN, N. The impact of board composition and ownership on audit quality: Evidence from large UK companies. The British Accounting Review, [S. I.], v. 32, n. 4, p. 397-4 I4, 2000.

OECD. OECD Principles of Corporate Governance. Organization for Economic Cooperation and Development, 2004. Disponível em: <http://www.oecd.org>. Acesso em: 04 abr. 2014.

PETROVIC, J. Unlocking the role of a board director: a review of the literature. Management Decision, [S.I.], v. 46, n. 9, p. I373-1392, 2008.

TIROLE, Jean. The Theory of Corporate Governance. Princeton, NJ: Princeton University Press, p. 15-73, 2006.

VAN DEN BERGHE, L.A.; BAELDEN, T. The monitoring role of the board: one approach does not fit all. Corporate Governance: An International Review, [S. I.], v. I3, n. 5, p. 680-690, 2005.

VERGARA, S. C. Projetos e relatórios de pesquisa em administração. I3. ed. São Paulo: Atlas, 20I I. 